\title{
Value-Based Management and Agile Methods
}

\author{
John Favaro \\ Consulenza Informatica \\ Pisa, Italy \\ jfavaro@tin.it
}

\begin{abstract}
Agile methods strive for clarity at the level of operations. Value Based Management strives for clarity at the level of the business. This paper discusses how they complement each other. Particular attention is focused on metrics for measuring value creation and efficient resource usage.
\end{abstract}

\section{Keywords}

Management, options, strategy, finance, metrics, economic profit.

\section{INTRODUCTION}

Agile methods such as Extreme Programming [1] are essentially focused on the operations of a business: in practice they are executed within the overall context of strategic and financial principles embodied either explicitly or implicitly in a particular management approach. However, they do contain elements of strategy and finance (such as a defined interaction with a Business actor) that give rise to biases that can make them more compatible with one management approach than another.

Value Based Management (VBM) is an integrated strategic and financial approach to the general management of businesses [2]. Value Based IT Management (VBIM) was introduced in 1998 as an approach to managing investment in reusable software, and has since been applied to other types of IT investment. The principal extension with respect to general VBM is the inclusion of options-oriented valuation techniques.

We recapitulate here the five principles of VBIM that were introduced in [3]:
A. Economic value maximization drives IT investment strategies for the business.
B. Strategy drives selection of IT investments.
C. IT Investments are actively structured to maximize embedded strategic options.
D. Both traditional discounted cash flow (DCF) and options-based techniques are used to capture the full value of IT investments.

E. Metrics are used to measure and guide performance.

Although each principle leads to the next in logical sequence, we take them out of order in this paper for purposes of exposition.

\section{THE TOMATO GARDEN METAPHOR}

We begin with Principle C, which expresses the concept of active management for strategic options. The view of XP as an options-driven process was introduced as early as the white book [1]. In another perspective, Luehrmann compares the management of a portfolio of strategic options to growing a garden of tomatoes in an unpredictable climate.

"Walk into the garden on a given day in August, and you will find that some tomatoes are ripe and perfect. Any gardener would know to pick and eat those immediately. Other tomatoes are rotten; no gardener would ever bother to pick them. These cases at the extremes - now and never-are easy decisions for the gardener to make. In between are tomatoes with varying prospects." [4]

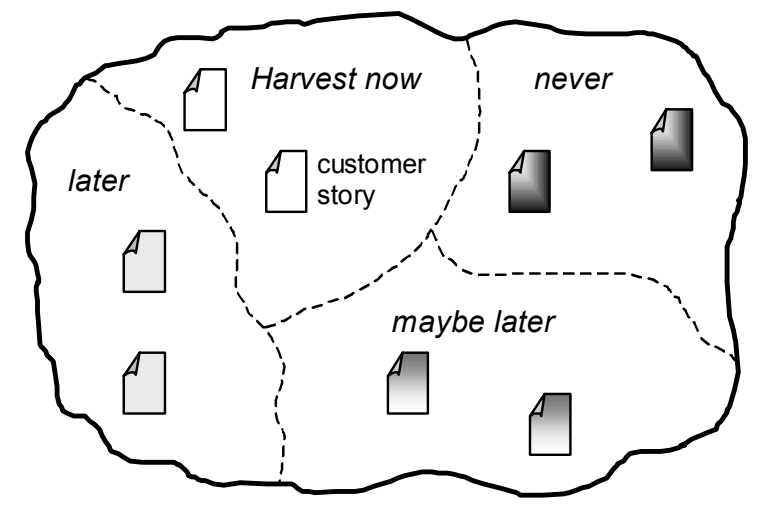

Figure 1: The tomato garden metaphor

Walk into an XP project on a given day and you will find a set of stories with varying prospects (Figure 1). Some can be scheduled for immediate implementation. A few might be clearly impossible to implement and are discarded.

"Some are edible and could be picked now but would 
benefit from more time on the vine."

That is, some stories would benefit from deferral to later iterations (e.g. until requirements become clearer).

“A purely passive gardener ... picks the ripe tomatoes and goes home. Active gardeners [not only] watch the garden but, based on what they see, they also cultivate it: watering, fertilizing, weeding."

Active management of an XP project involves continuous cultivation through techniques such as refactoring, automated tests, and daily builds in an effort to maximize the strategic options available at any time.

"Of course, the weather is always a question, and not all the tomatoes will make it. Still, we'd expect the active gardener to enjoy a higher yield in most years than the passive gardener."

Although external uncertainties can always conspire to undermine the success of a project, we expect the active management of strategic options through the XP practices to produce better results than a traditional "fire and forget" methodology.

\section{THE ROLE OF STRATEGY}

Principle B concerns the role of strategy in driving the business. It is nearly always futile to try to predict with confidence the economic benefits of a single action on an individual project — or tomato garden—due to the multitude of unknowns (and even "unknown unknowns," the socalled unk-unks) facing it at any time.

In such a climate of uncertainty, a higher-level strategic framework that links entire strategies to value creation at the level of the business is needed.

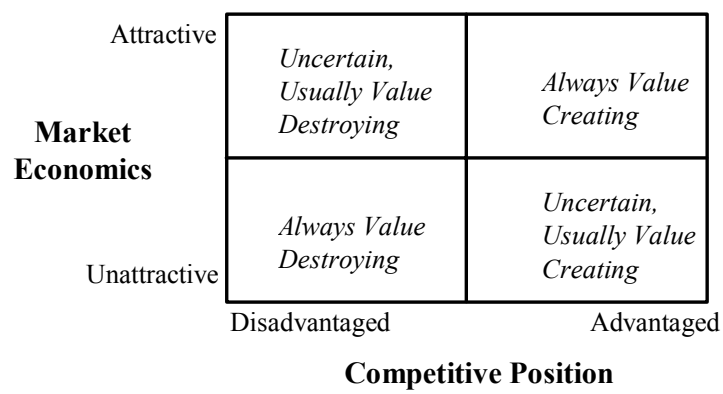

Figure 2: ME/CP framework

The ME/CP framework (Marakon Associates) was described in detail in 1999 in the context of a strategic analysis of application framework development [8]. As seen in Figure 2, there are two (and only two) primary determinants of business value creation: market economics and competitive position.

\section{Market economics}

Over time, the average tomato gardener working in the fertile soil of southern Italy will be more profitable than the average gardener working in the arid soil of the Sahara desert. Likewise, a software enterprise working in a market where the average participant is profitable (such as the mutual fund industry) is more likely to experience business value creation than a participant in a market with less attractive economics. At the operational level, agile methods support the creation of strategic options both for entry into profitable market situations, and exit from unprofitable ones, as discussed in detail in [6].

\section{Competitive position}

Notwithstanding the vast literature on competitive practice, the $\mathrm{ME} / \mathrm{CP}$ framework tells us that there are ultimately only two ways to improve competitive position: through a lower economic cost position or through successful differentiation. The financial contribution of lower costs (and the operational contribution of agile methods in this respect) is well understood. But the value-based interpretation of differentiation is often misunderstood: the gardener who succeeds in producing the most delicious tomatoes in the world has not achieved differentiation if he cannot exploit this achievement either to (a) sell his tomatoes at a higher price or (b) hold prices while gaining market share.

Differentiation provides us with a good illustration of the difference between an operational methodology and a strategic/financial methodology. Operational skills offer support, but differentiation occurs at the level of the business. In the case of tomatoes, it might be the bright red color rather than the flavor that enables differentiation (try a tomato from Holland sometime); in the case of software it may be a particular feature that customers are willing to pay for. The search for differentiating features occurs at the level of the business, through the chosen framework that guides the business toward value-adding strategies; agile methods are particularly good in supporting that search for differentiation by their many feature-oriented practices (especially the organization of projects along user stories at the granularity of individual features).

\section{VALUATION}

Although operational methodologies offer support in the pursuit of business value, it is the job of the strategic/financial framework to provide the definition of "value" that becomes the basis for evaluating a project. This is the subject of principle D.

Value based management provides such a definition, in terms of Present Value: the expected future period $i$ cash flows $C_{i}$ of a project, discounted back to the present at the opportunity cost of money $k$. The familiar basic formula is: 
$\mathrm{PV}=\frac{C_{1}}{(1+k)}+\frac{C_{2}}{(1+k)^{2}}+\ldots$

A comparative analysis in 1996 illustrated how the Present Value approach is superior to other techniques for project valuation such as "time to payback" or "cost-benefit ratio" [14]. Option theoretic techniques that augment Present Value techniques to capture the value of strategic options have been introduced in VBIM and were discussed at length in [6].

\section{ECONOMIC VALUE MAXIMIZATION}

The subject of Principle A is the governing objective of an enterprise. Every company has a governing objective, although it is often only implicitly expressed in the way it conducts its business. At first glance, it may seem like some kind of abstract "mission statement" for a company, but its role is actually a very practical one - to provide a decision-making and conflict-resolution principle to the hundreds, usually thousands of business decisions that are carried out every day at all levels in the enterprise, from company headquarters all the way down to the business units and individual projects.

There is a strong tendency for a company to set a strategic, or product-market oriented governing objective:

- achieving the highest possible quality

- maximizing growth of the business

- maximizing customer satisfaction

There are several management styles that support these kinds of governing objectives. An alternative governing objective is financial: maximizing the economic value of the company (or business unit) over time. This is the governing objective supported by VBM. What is meant by "economic value"? Principle $\mathrm{C}$ gives us a precise definition: the discounted present value of future cash flows.

Some argue that a strategic and a financial governing objective are effectively equivalent - that each automatically leads to better financial performance. To see why not, let's take a concrete example. Phrases such as "Customer Value" often arise in discussions of agile methodologies. Suppose that our declared governing objective is "maximizing customer value." Such a governing objective generally contains the assumption, often only implicit, that maximizing customer satisfaction will automatically lead to superior financial performance. Paul Allaire, CEO of Xerox, once put it this way: "If we do what's right for the customer, our market share and our return on assets will take care of themselves." [9]

This assumption is more tenuous than it appears, though. In fact, conflicts between customer satisfaction and economic return arise continuously in practice, as was illustrated in 1996 in a graph (Figure 3) that shows four possible scenarios [12]. Scenarios 1 and 4 are the extreme cases and also the simplest: more satisfied customers lead to better economic returns and vice versa. But the other two scenarios are much more common. Scenario 2 illustrates the case where the effort and expense invested have paid off in terms of customer satisfaction, but the economic returns have been insufficient to cover the investment. When a product has overshot the peak, it is effectively subsidizing the customer. The only recourse is to try to move back up the curve, as in Scenario 3, by providing a better balance between value and price. Often this involves removing features that are not essential to customer satisfaction - for example, providing a "lite" version of the product that retains an adequate level of customer satisfaction but lowers production costs.

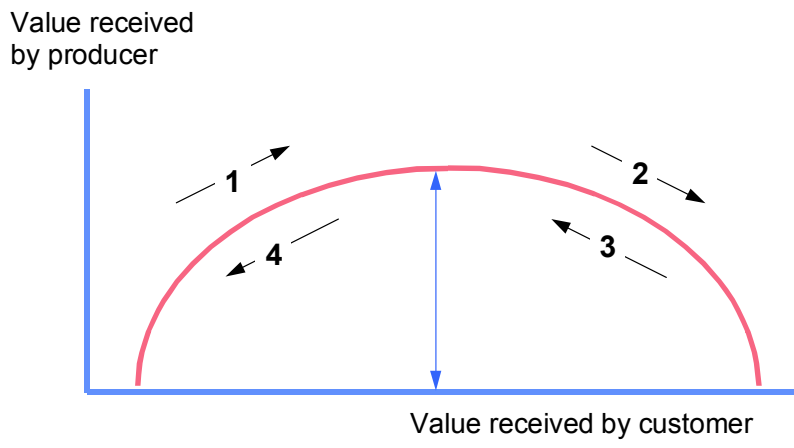

Figure 3: Producer and customer value conflicts

Customer Value (or any other purely strategic objective) is not suitable as a top-down, corporate-level objective. A business unit, or even a project, should receive only the instructions from upper management to maximize its economic value. It is up to the business unit or project to determine - in its own particular context-whether customer value should become a strategic weapon in pursuit of that objective. The operational elements of agile methodologies are well suited to supporting this economic objective, with their approach of continuous feedback and re-estimation of both customer and producer value, yielding the information needed by decision-makers in the conflict resolution process. For example, agile methodologists stress the importance of identifying explicit costs with requirements at the individual level [5]. In another example, on program optimization, Fowler writes that "one value of an explicit optimization phase is that the cost of getting fast performance is more explicit, so businesses can trade it against time to market or more features." [11]

\section{VALUE BASED METRICS}

"The basic XP management tool is the metric [1]." 
Principle E concerns metrics. We will dwell a bit longer on this topic because it is currently a subject of much interest in the agile community, and because metrics based on value are not yet described elsewhere in the literature on VBIM.

A number of metrics are cited in the agile method literature, such as:

- Ratio between estimated development time and calendar time;

- Unit test scores;

- Functional test scores.

These metrics play a highly visible role in agile methods for measuring and providing feedback on operational performance, helping to provide a signal of how well the project is proceeding. Similarly, in VBM, metrics play a highly visible role in measuring and providing feedback on financial performance, helping to provide a signal of whether business value is being created or destroyed. As discussed in earlier sections, these metrics are at the level of the business, whereas operational metrics like those mentioned above only give indirect support. Nevertheless, as mentioned in the beginning of this paper, the agile approach to software development has given rise to some biases that makes it particularly well aligned with valuebased thinking about business value creation. We are beginning to see this bias in a new set of measures being proposed within the agile community.

One type of new measure that has been gaining credence from several different sides in the agile community is related to the idea of "software inventory." An example is the metric Beck recently suggested as "software in process," suggesting an analogy to the "work in process" term that is used for classifying inventory [13]. The Lean Software Development paradigm [10] is also closely associated with the analogy to inventory management. The preoccupation with inventory in both cases is indicative of a general preoccupation in agile methods with efficient use of resources. The principles of small teams, small documentation, and minimized upfront design all have to do with this.

Let us see now how this emerging way of thinking about agile performance is compatible with the financial performance metrics used in VBM. What is "performance" in a value-based sense? Principles A and D together give us the answer: creating economic value. This leads to the next question: how can economic value creation be measured? We need a financial metric that is aligned with the principle of maximization of economic value-that is, discounted cash flows - and at the same time measures (and encourages) efficient and effective use of capital resources.

\section{Measuring profitability}

In essence, all financial metrics concern the measurement of profitability. In its most basic expression, profit consists simply of earnings $(E)$ after costs are subtracted. Similarly, in its most basic expression, Return On Investment (ROI) consists simply of the ratio of earnings to the amount invested $(I)$ :

ROI $=\frac{E}{I}$

For example, a project with $\$ 1000$ invested and earnings of $\$ 100$ each month has an ROI of $10 \%$ per month.

\section{Economic Profit}

Businesses often measure profitability using this definition of ROI-but in doing so, they are measuring operating profits, which are missing one key element of value creation: they don't take into account the cost of the capital (labor, equipment, etc.) that was employed in generating those profits. This is the key characteristic of the metric used in VBM, known as Economic Profit (EP) [2].

EP has its origins in the idea of residual income, a concept that is well over a century old. Writing in 1890, Marshall noted that "what remains of [a manager's] profits after deducting interest on his capital at the current rate may be called his earnings of undertaking or management." [7] The use of residual income as a financial metric has been popularized most in recent years in a variation that was promoted (and copyrighted) by the firm Stern Stewart as Economic Value Added or simply EVA ${ }^{\odot}$. It is conceptually equivalent to EP.

Economic Profit deducts a charge for the capital employed in generating operating profits. Why? Because capital does have a cost. That cost is $k$, the opportunity cost of capital that appears in the present value formula. Economic Profit is defined as

$\mathrm{EP}=C-I \times k$

where

- $\quad C$ is the cash flow (earnings) generated by the project;

- $I$ is the amount of the investment;

- $k$ is the opportunity cost of capital.

The $I \times k$ term is the "capital charge" on earnings.

In order to understand this idea, let us go back to the basic concept of opportunity cost: it is the return that investors demand from the project. If a project is earning an ROI of $10 \%$, as in our example, it is fine if the investors only demanded an $8 \%$ return. But if they demanded a $15 \%$ return, then business value is not being created for them-it 
is being destroyed. An equivalent formulation of EP makes this idea clear:

$$
\mathrm{EP}=I \times(\mathrm{ROI}-k)
$$

This formulation demonstrates that value is being created only if the project has an ROI above its cost of capital. In our example, if investors demanded an $8 \%$ return, then

$\mathrm{EP}=\$ 1000 \times(10 \%-8 \%)=\$ 20$

But if investors demanded a 15\% return, then

$\mathrm{EP}=\$ 1000 \times(10 \%-15 \%)=-\$ 50$

In each case, the operating profit is $\$ 100$; but the economic profit after the capital charge reveals that only in the first case is business value being created for the investors - that is, profit over and above the minimum rate of return expected by them.

\section{Making the cost of capital explicit}

The Economic Profit metric is completely aligned with the definition of value in VBM: in fact, it can be shown that representing project value as a stream of economic profits is equivalent to representing it with the standard discounted cash flow formula (see the Appendix for details).

Why, then, not directly use the discounted cash flow formula as a metric? The reason is that DCF, as a forwardlooking calculation, cannot give an ongoing signal about what is happening in the project-in particular, about whether value is being created or destroyed; and neither do traditional metrics like ROI or earnings. Reporting that a project is earning $-\$ 50$ in Economic Profit sends a much stronger signal about what is really happening than reporting that a project is earning $\$ 100$ or has an ROI of $10 \%$, even though all of these metrics are communicating the same information. Analogous to Fowler's example of optimization in the previous section, the Economic Profit metric makes the cost of capital explicit.

\section{Monitoring efficient resource usage}

Making the cost of capital explicit forces a manager to think twice before lavishing a project with more resources than are needed to accomplish its goals. On the contrary, it encourages him to eliminate waste in any form, from needless man-hours spent in upfront design to bloated programming teams to unneeded office space.

The results in management behavior obtained from switching over to this type of financial metric can be dramatic, whether in software or any other industry. Consider this observation about the effect on management practices within the Quaker Oats Company:

“... its businesses had one overriding goal-increasing quarterly earnings. To do it, they guzzled capital. They offered sharp price discounts at the end of each quarter, so plants ran overtime turning out huge shipments ... the pernicious practice known as trade loading (because it loads up the trade, or retailers, with product) and many consumer product companies are finally admitting it damages long-run returns. An important reason is that it demands so much capital. Pumping up sales requires many warehouses (capital) to hold vast temporary inventories (more capital). But who cared? Quaker's operating businesses paid no charge for capital in internal accounting, so they barely noticed." [15]

(The problem went away with the capital charge metric.)

The alignment of many of the operating principles promoted by agile methods with this financial principle is remarkable: use all the resources you need, but only the resources you need. Agile metrics monitor the effects on operations; Economic Profit monitors the effects on business value.

\section{Profitability and growth}

Software development managers, like those in any business, are often obsessed with growth: bigger teams; more powerful equipment; more investment in support software; elaborate, labor-intensive processes-effectively, a governing objective of "maximizing growth." One financial motivation for this phenomenon of "empire building" is that a larger capital base makes it possible to boost earnings. As a simple illustration, at the same level of ROI in our example, a manager could invest another $\$ 1000$ and double his earnings to $\$ 200$ per month.

But the agile movement has instinctively understood that not all growth is necessarily good. From an operating perspective, agile principles tell us that undisciplined growth can cause a project to reel out of control, and admonishes us to "start small." From a financial perspective, VBM tells us that unprofitable growth will destroy value and admonishes us to measure Economic Profit before making a decision to grow. In our example, doubling the invested capital when the project is earning below its cost of capital will double the economic loss.

Not all growth must be bad: measuring Economic Profit makes it possible not only to avoid value-destroying growth, but also to identify value-creating growth opportunities. If a project has a high level of Economic Profit on low invested capital, then an opportunity to increase capital expenditure and generate higher profits has been identified.

\section{CONCLUSIONS}

The operating principles embodied in agile methods make operating parameters explicit; the financial and strategic principles embodied in Value Based Management make profitability parameters explicit. They make a good pair. -5 - 


\section{REFERENCES}

[1] Beck. K., Extreme Programming Explained: Embrace Change, Addison-Wesley, 1999.

[2] McTaggart, J. M., P.W. Kontes, and M.C. Mankins, The Value Imperative, The Free Press, 1994.

[3] Favaro, J.M., K.R. Favaro and P.F. Favaro, "Valuebased software reuse investment," Annals of Software Engineering 5, pp. 5-52, 1998.

[4] Luehrman, T. A., "Strategy as a portfolio of real options," Harvard Business Review, September 1998.

[5] Favaro, J.M., "Managing Requirements for Business Value," IEEE Software, March 2002.

[6] Erdogmus, H. and J.M. Favaro, "Keep your options open: Extreme Programming and the economics of flexibility," in Extreme Programming Perspectives, M. Marchesi, G. Succi, D. Wells and L. Williams, Editors: Addison-Wesley, 2003.

[7] Marshall, A., Principles of Economics, Vol. 1, MacMillan \& Co., New York, 1890.

[8] Favaro, J. M. and K. R. Favaro, "Strategic Analysis of Application Framework Investments," in Building Application Frameworks: Object Oriented Foundations of Framework Design, M. Fayad and R. Johnson, Editors: John Wiley and Sons, 1999.

[9] Harari, O., "You're Not in Business to Make a Profit," Management Review, July 1992, pp. 53-55.

[10] Poppendieck, M., Lean Development: A Toolkit for Software Development Managers, Addison-Wesley, 2003.

[11] Fowler, M., "Yet Another Optimization Article," IEEE Software, May 2002.

[12] Favaro, J.M., "When the Pursuit of Quality Destroys Value," IEEE Software, May 1996.

[13] Beck, K., "Software-in-Process: A New/Old Project Metric," September 2002, working paper, http://groups.yahoo.com/group/softwareinprocess

[14] Favaro, J. M., “A comparison of approaches to reuse investment analysis," Proc. Fourth International Conference on Software Reuse, IEEE Computer Society Press, Los Alamitos, CA, pp. 136-145.

[15] Tully, S., "The Real Key to Creating Shareholder Wealth," Fortune, 20 September 1993.

\section{APPENDIX}

In this appendix we demonstrate more formally that the Economic Profit metric is fully aligned with the definition of value creation in Value Based Management. We will take the simple case of a project where there is a single initial investment $I$ followed by cash flows $C_{t}$ over an indefinite number of time periods. The cash flows are discounted at a rate $k$, corresponding to the cost of capital for the project. According to the DCF formula, the value of the project (its present value) is

$\mathrm{PV}=\frac{C_{1}}{(1+k)}+\frac{C_{2}}{(1+k)^{2}}+\frac{C_{3}}{(1+k)^{3}}+\ldots$

and its net present value is

$\mathrm{NPV}=\mathrm{PV}-I$

In order to arrive at an expression of cash flows in terms of Economic Profit, recall the definition of Economic Profit:

$\mathrm{EP}=C-I \times k$

Therefore, in any time period $t$,

$C_{t}=\mathrm{EP}_{t}+I \times k$

Now we substitute into the present value formula:

$$
\begin{aligned}
\mathrm{PV} & =\sum_{t=1}^{\infty} \frac{C_{t}}{(1+k)^{t}}=\sum_{t=1}^{\infty} \frac{\mathrm{EP}_{t}+I \times k}{(1+k)^{t}} \\
& =\sum_{t=1}^{\infty} \frac{\mathrm{EP}_{t}}{(1+k)^{t}}+\sum_{t=1}^{\infty} \frac{I \times k}{(1+k)^{t}} \\
& =\sum_{t=1}^{\infty} \frac{\mathrm{EP}_{t}}{(1+k)^{t}}+I \times \sum_{t=1}^{\infty} \frac{k}{(1+k)^{t}}
\end{aligned}
$$

Noting that the last summation involves an infinite geometric series and converges to 1 , we have

$\mathrm{PV}=I+\sum_{t=1}^{\infty} \frac{\mathrm{EP}_{t}}{(1+k)^{t}}$

Therefore, the value of a project can be expressed either as

Value $=$ present value of all future cash flows

(more appropriate for use in forward-looking valuations)

or as

Value $=$ initial investment + present value of all future economic profits

(more appropriate for use in period-by-period measurement of value creation). 